\title{
A comparison between ketorolac and nefopam as adjuvant analgesics for postoperative patient-controlled analgesia: a randomized, double-blind, prospective study
}

\author{
Ji-Seon Son, Aram Doo, Young-Jun Kwon, Young-Jin Han, and Seonghoon Ko \\ Department of Anesthesiology and Pain Medicine, Chonbuk National University Medical School and Hospital, \\ Jeonju, Korea
}

Background: We compared the analgesic efficacy and side effects of ketorolac and nefopam that were co-administered with fentanyl via intravenous patient-controlled analgesia.

Methods: One hundred and sixty patients scheduled for laparoscopic cholecystectomy were randomly assigned to ketorolac (Group K) or nefopam (Group N) groups. The anesthetic regimen was standardized for all patients. The analgesic solution contained fentanyl $600 \mu \mathrm{g}$ and ketorolac $180 \mathrm{mg}$ in Group K, and fentanyl $600 \mu \mathrm{g}$ and nefopam $120 \mathrm{mg}$ in Group $\mathrm{N}$. The total volume of analgesic solution was $120 \mathrm{ml}$. Postoperative analgesic consumption, recovery of pulmonary function, and pain intensities at rest and during the forced expiration were evaluated at postoperative 2, 6, 24, and $48 \mathrm{~h}$. The postoperative side effects of analgesics were recorded.

Results: Cumulative postoperative analgesic consumptions at postoperative $48 \mathrm{~h}$ were comparable (Group K: $93.4 \pm 24.0$ $\mathrm{ml}$ vs. Group N: $92.9 \pm 26.1 \mathrm{ml}, \mathrm{P}=0.906$ ) between the groups. Pain scores at rest and during deep breathing were similar at the time of each examination. The recovery of pulmonary function showed no significant differences between the groups. Overall, postoperative nausea and vomiting incidence was higher in Group N compared with Group K (59\% vs. $34 \%, \mathrm{P}=0.015)$. The other side effects were comparable between both groups.

Conclusions: Analgesic efficacies of ketorolac and nefopam that were co-administered with fentanyl for postoperative pain management as adjuvant analgesics were similar. However, postoperative nausea and vomiting incidence was higher in the nefopam-fentanyl combination compared with the ketorolac-fentanyl combination.

Key Words: Ketorolac, Nefopam, Patient-controlled analgesia, Postoperative pain.

Corresponding author: Seonghoon Ko, M.D., Ph.D.

Department of Anesthesiology and Pain Medicine, Chonbuk National University Medical School and Hospital, 20, Gunji-ro, Deokjin-gu, Jeonju 54907, Korea

Tel: 82-63-250-1979, Fax: 82-63-250-1240, Email: shko@jbnu.ac.kr

ORCID: https://orcid.org/0000-0003-2742-9985

It was presented at The 92nd Annual Scientific Meeting of the Korean Society of Anesthesiologists, November 2015, BEXCO Convention Hall, Busan, Korea.

Received: February 27, 2017. Revised: March 24, 2017. Accepted: March 29, 2017.

Korean J Anesthesiol 2017 December 70(6): 612-618

https://doi.org/10.4097/kjae.2017.70.6.612

(c) This is an open-access article distributed under the terms of the Creative Commons Attribution Non-Commercial License (http://creativecommons.org/ licenses/by-nc/4.0/), which permits unrestricted non-commercial use, distribution, and reproduction in any medium, provided the original work is properly cited. 


\section{Introduction}

Intravenous patient-controlled analgesia (IV-PCA) with opioids is the most commonly utilized method for acute postoperative pain management after a major operation because opioids are appropriate for controlling severe pain due to a lack of ceiling effects [1]. However, the use of postoperative opioids is associated with delayed recovery from anesthesia, postoperative nausea and vomiting (PONV), dizziness, pruritus, and respiratory depression [2-4]. In order to minimize the risk of opioidrelated adverse effects and maintain effective pain control, the combined use of opioids with adjuvant analgesics such as nonsteroidal anti-inflammatory drugs (NSAIDs) is a good option $[5,6]$. The adjuvant analgesics decrease opioid-related side effects with an opioid-sparing effect, and add a different analgesic action from opioids when used in combination.

Ketorolac tromethamine is a NSAID that inhibits cyclooxygenase (COX) activity in the arachidonic acid cascade and interferes with various inflammatory substances involved in the sensitization of nociceptors. NSAIDs are the most commonly used adjuvants of opioids for postoperative pain management $[7,8]$. Nefopam is a centrally acting non-opioid, non-steroidal analgesic that inhibits the reuptake of serotonin, norepinephrine, and dopamine [9]. Ketorolac and nefopam have no postoperative sedative and respiratory depression effects compared with opioids and they have unique analgesic mechanisms that are different from opioids. Furthermore, previous studies have established the analgesic efficacy and safety of ketorolac and nefopam in various surgical settings [10-13].

Many previous studies have demonstrated the analgesic efficacy and opioid-sparing effect of ketorolac and nefopam separately [14-16]. However, no study has compared the effects of ketorolac and nefopam as an adjuvant analgesic to opioid in postoperative PCA. The authors hypothesized that ketorolac and nefopam that were co-administered with fentanyl would show different analgesic efficacy and side effects because they have different action mechanisms. Therefore, we conducted this prospective, randomized, double-blinded study to compare the analgesic efficacy and side effects of ketorolac and nefopam that were co-administered with fentanyl via IV-PCA for postoperative analgesia after laparoscopic cholecystectomy.

\section{Materials and Methods}

This prospective, randomized, double-blind study was approved by the Institutional Review Board of the author's institution and registered with the WHO International Clinical Trials Registry Platform (KCT0001656). Written informed consent was obtained from all patients. One hundred and sixty patients, American Society of Anesthesiologists physical status I or II and aged 20 to 70 years, undergoing elective laparoscopic cholecystectomy were enrolled. Exclusion criteria were the use of analgesics, sedatives, or antidepressants within $48 \mathrm{~h}$ prior to surgery, alcohol or drug abuse, the presence of hepatic, renal, cardiopulmonary, hematologic, or psychological disorder, known intolerance or hypersensitivity to ketorolac, nefopam, and fentanyl, a history of motion sickness or PONV, or inability to understand the use of PCA. The four major risk factors of PONV are female gender, non-smoking, use of postoperative opioids, and prior history of motion sickness or PONV according to Apfel's simplified risk scoring system [17]. Because patients received fentanyl postoperatively and those who have a history of motion sickness or PONV were excluded, the enrolled patients in this study had one to three of PONV risk factors.

Subjects were randomly assigned by computer-generated random numbers to ketorolac (Group K) or nefopam (Group $\mathrm{N}$ ) groups. We explained the use of the IV-PCA device (Accumate $1100^{\circledR}$, Wooyoung Meditech, Seoul, Korea) and numerical rating scale (NRS; $0=$ no pain, $10=$ worst pain imaginable) for pain rating to each patient during the preanesthetic visit on the day before surgery. In addition, preoperative values of forced vital capacity (FVC) and forced expiratory volume in $1 \mathrm{sec}$ (FEV1) were obtained with a portable pulmonary function test device (Contec ${ }^{\circledR}$ spirometer, Contec Medical System Co., Qinhuangdao, China).

No premedication was given for all patients. After placement of electrocardiogram, pulse oximetry, noninvasive blood pressure, bispectral index (BIS), and peripheral nerve stimulator, standard anesthetic regimens and techniques were used for all patients. Anesthesia was induced with $2-2.5 \mathrm{mg} / \mathrm{kg}$ propofol and $0.6-0.8 \mathrm{mg} / \mathrm{kg}$ rocuronium. The patients were manually ventilated via a face mask with sevoflurane 4.0 vol\% in $50 \%$ oxygen until a train-of-four count of 0 in the peripheral nerve stimulator (TOF watch ${ }^{\circledR}$, Organon Ltd., Dublin, Ireland). After orotracheal intubation, temperature was monitored at the nasopharynx and the patients were warmed by a forced-air warming system. Anesthesia was maintained with sevoflurane 1-4 vol\% in $50 \%$ oxygen. Fresh gas flow rate was maintained at $3 \mathrm{~L} / \mathrm{min}$ during the operation. End-tidal carbon dioxide partial pressure and BIS value were maintained at 30 to $35 \mathrm{mmHg}$ and $40-60$, respectively. Arterial blood pressure was kept within $20 \%$ of preanesthetic values by adjustment of inspired sevoflurane concentration. If a patient showed a mean arterial pressure of $<60$ $\mathrm{mmHg}$ despite decreasing sevoflurane concentration to $1 \mathrm{vol} \%$, the patient received ephedrine. At the end of surgery, sevoflurane was discontinued and the patients were ventilated with a high fresh gas flow (> $8 \mathrm{~L} / \mathrm{min}$ ) and received neostigmine and glycopyrrolate for reversal of neuromuscular blockade.

All patients were equipped with an IV PCA device for 48 hours. The analgesic solution contained fentanyl (Hana fentanyl 
citrate, Hana Pharm Co., Seoul, Korea) $600 \mu \mathrm{g}$ and ketorolac (Trolac, Whanin Pharm Co., Seoul, Korea) $180 \mathrm{mg}$ in Group $\mathrm{K}$ and fentanyl $600 \mu \mathrm{g}$ and nefopam (Acupan, Phambio Korea, Seoul, Korea) $120 \mathrm{mg}$ in Group N. Previous studies have reported that both nefopam $20 \mathrm{mg}$ and ketorolac $30 \mathrm{mg}$ have equianalgesic potency to $12 \mathrm{mg}$ of morphine $[18,19]$. Therefore, the authors considered $180 \mathrm{mg}$ of ketorolac and $120 \mathrm{mg}$ of nefopam as equipotent. The total volume of analgesic solution was $120 \mathrm{ml}$. Patients were administered a loading dose of PCA (0.1 $\mathrm{ml} / \mathrm{kg}$ analgesic solution) at skin closure for $20 \mathrm{~min}$. No adjuncts for postoperative pain were allowed. Initial PCA settings were 1 $\mathrm{ml} / \mathrm{h}$ background infusion, demand bolus dose of $3 \mathrm{ml}$, lockout interval of $7 \mathrm{~min}$, and 6 times of $1 \mathrm{~h}$ limitation.

The primary endpoints of the study were postoperative analgesic consumption and pain intensity and the secondary endpoint was incidences of side effects. The postoperative analgesic solution consumption was recorded at postoperative 2 , 6,24 , and $48 \mathrm{~h}$. Postoperative pain intensities at rest and during forced expiration were evaluated by NRS during examination. The NRS pain scores were measured by an anesthesiologist who was blinded to the study groups to exclude inter-rater bias. The postoperative side effects of analgesics such as dizziness, sweating, hypotension, bradycardia, tachycardia, PONV, urinary retention, pruritus, somnolence, and respiratory depression were recorded. The postoperative recovery values of FVC and FEV1 were assessed at each time point. All patients were monitored in the postanesthesia care unit (PACU) for $2 \mathrm{~h}$ before discharge to surgical ward.

\section{Statistical analysis}

A pilot study of 10 patients from Group K revealed analgesic solution consumption during the postoperative $48 \mathrm{~h}$ with an average of $100 \mathrm{ml}$ and a standard deviation of $35 \mathrm{ml}$. For $48 \mathrm{~h}$ of cumulative postoperative analgesic solution consumption, we considered a difference of $\geq 20 \mathrm{ml}$ to be clinically significantly. It was determined that 66 patients were required in each group to obtain a difference in mean analgesic solution consumption of $20 \mathrm{ml}$ for an expected standard deviation of $35 \mathrm{ml}$ at a significance level of $0.05(\alpha=0.05)$ and a power of $90 \%(\beta=0.10)$. To allow for attrition, the sample size was enlarged to 150 .

Statistical analysis was performed with SigmaPlot 12.0 (Systat Software Inc. San Jose, USA). Data are presented as mean \pm SD, or median (interquartile range). Patient characteristics and anesthesia time were analyzed with unpaired t-test or Chi-square test. Analgesic consumption was compared with unpaired t-test at each time point. The postoperative pain intensities measured by NRS within group and between groups at each time were analyzed using "one-way repeat measured ANOVA" rank sum test and Mann-Whitney rank sum test, respectively. Incidences

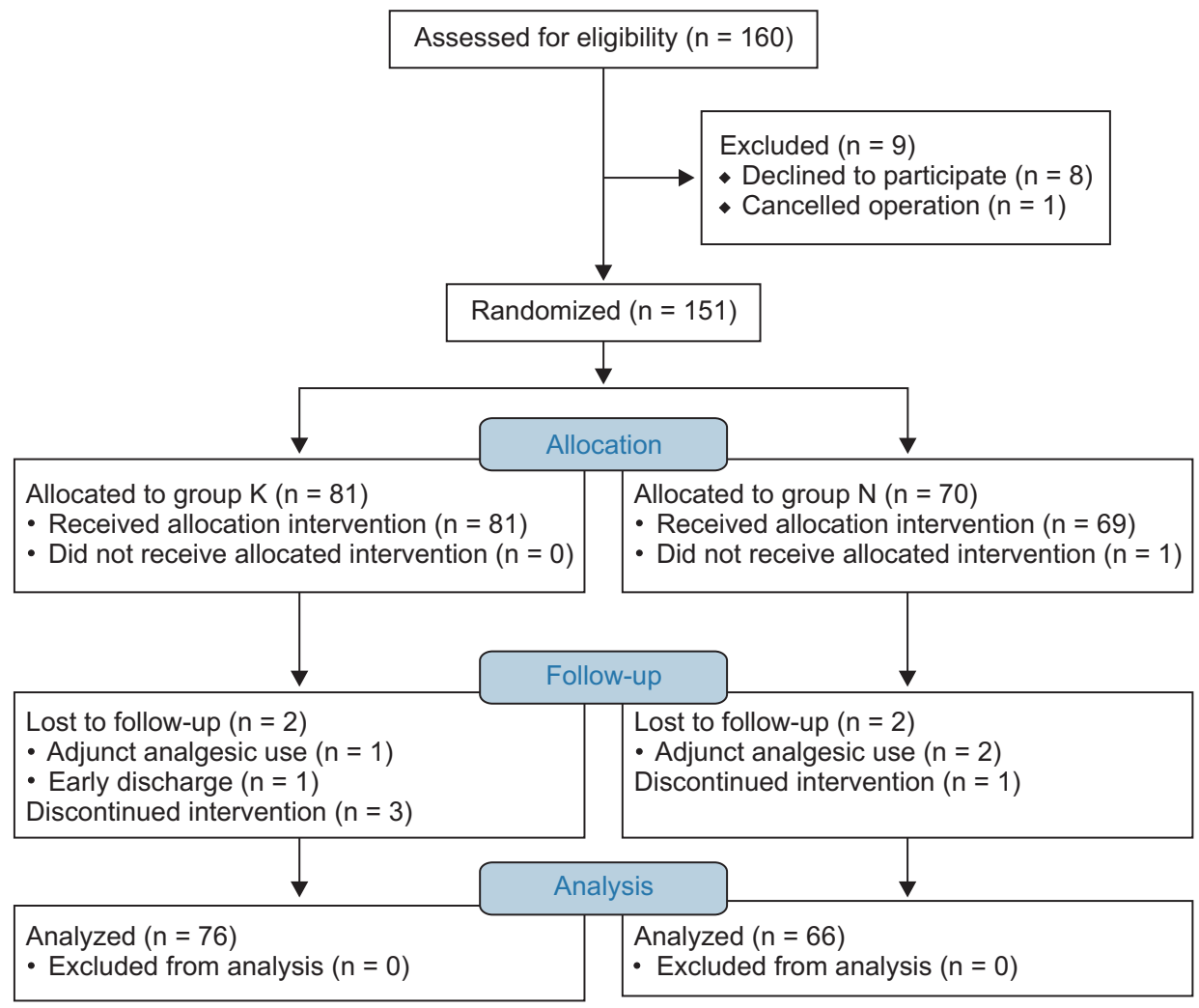

Fig. 1. Study flow chart according to the CONSORT statement. 
Table 1. Patient Characteristics

\begin{tabular}{lccc}
\hline & $\begin{array}{c}\text { Group K } \\
(\mathrm{n}=76)\end{array}$ & $\begin{array}{c}\text { Group N } \\
(\mathrm{n}=66)\end{array}$ & P values \\
\hline Age $(\mathrm{y})$ & $47.6 \pm 10.3$ & $45.7 \pm 9.8$ & 0.277 \\
Gender $(\mathrm{F} / \mathrm{M})$ & $35 / 41$ & $33 / 33$ & 0.763 \\
Height $(\mathrm{cm})$ & $163.5 \pm 8.1$ & $164.4 \pm 8.4$ & 0.538 \\
Weight $(\mathrm{kg})$ & $65.9 \pm 11.9$ & $69.1 \pm 11.5$ & 0.113 \\
Duration of anesthesia (min) & $77.2 \pm 15.9$ & $79.6 \pm 15.4$ & 0.355 \\
Number of PONV risk factor $(1 / 2 / 3)$ & $20 / 21 / 35$ & $19 / 14 / 33$ & 0.676 \\
\hline
\end{tabular}

Data are presented as mean \pm SD and number of patients. Group $\mathrm{K}$ and $\mathrm{N}$ are the ketorolac-fentanyl and nefopam-fentanyl combinations, respectively. PONV: postoperative nausea and vomiting.

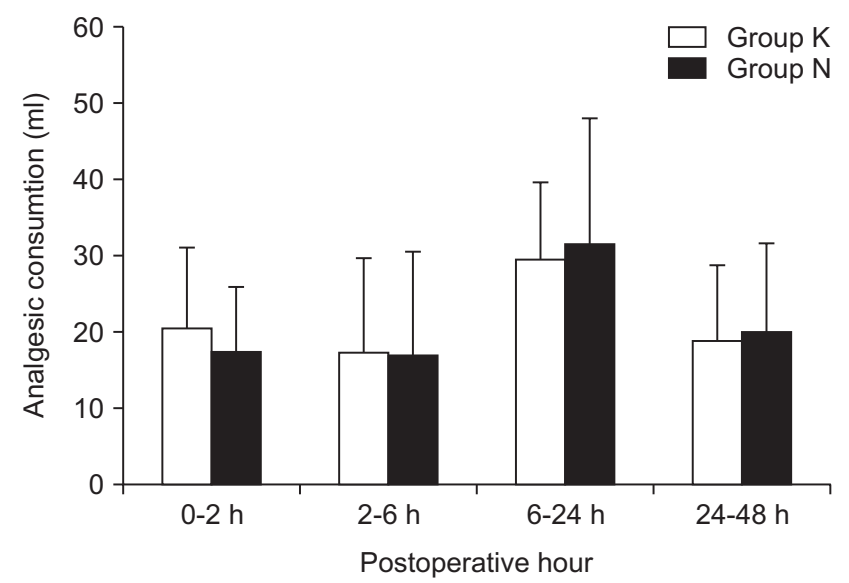

Fig. 2. There were no significant differences in analgesic consumptions at each measurement time point between both groups. Group $\mathrm{K}$ and $\mathrm{N}$ are the ketorolac-fentanyl and nefopam-fentanyl combinations, respectively.

of side effects were analyzed using Chi-square test. P values less than 0.05 were regarded as significant.

\section{Results}

One hundred and fifty-one patients were allocated into groups and the subject flow diagram is shown in Fig. 1. The two groups with remaining 142 patients completed the 48 -h follow-up with adequate pain relief. The characteristics of the patients and anesthesia time were comparable between the groups (Table 1).

Analgesic consumptions at postoperative 2, 6, 24, and $48 \mathrm{~h}$ were similar between the groups (Fig. 2). Cumulative postoperative analgesic consumptions at postoperative $48 \mathrm{~h}$ were similar between the groups (Group K: $93.4 \pm 24.0 \mathrm{ml}$ vs. Group N: 92.9 $\pm 26.1 \mathrm{ml}, \mathrm{P}=0.906)$. There were no significant differences in NRS pain scores at rest and during deep breathing between the groups and the pain scores at rest were less than 4 for both groups (Table 2). Pulmonary function as determined by FVC and FEV1 decreased after operation and increased gradually
Table 2. Postoperative Pain Intensities Measured by the Numerical Rating Scale

\begin{tabular}{lllll}
\hline & & $\begin{array}{c}\text { Group K } \\
(\mathrm{n}=76)\end{array}$ & $\begin{array}{c}\text { Group N } \\
(\mathrm{n}=66)\end{array}$ & P values \\
\hline \multirow{2}{*}{$\mathrm{h}$ h } & Rest & $4(3-5)$ & $4(3-5)$ & 0.917 \\
& Deep breath & $5(4-6.8)$ & $5(4-6)$ & 0.827 \\
$6 \mathrm{~h}$ & Rest & $3(2-4)$ & $3(2-4)$ & 0.403 \\
& Deep breath & $3(3-5)$ & $4(3-5)$ & 0.426 \\
$24 \mathrm{~h}$ & Rest & $2(1-3)$ & $2(1-3)$ & 0.273 \\
& Deep breath & $3(1.3-4)$ & $3(2-4)$ & 0.191 \\
$48 \mathrm{~h}$ & Rest & $1(1-2)$ & $1(1-2)$ & 0.976 \\
& Deep breath & $2(1-3)$ & $2(1-3)$ & 0.955 \\
\hline
\end{tabular}

Data are presented as median (interquartile range). Group $\mathrm{K}$ and $\mathrm{N}$ are the ketorolac-fentanyl and nefopam-fentanyl combinations, respectively.

over time. The 48-h postoperative values of FVC and FEV1 recovered to $90-91 \%$ and $93 \%$, respectively, compared with the preoperative values of FVC and FEV1. The recovery of FVC and FEV1 showed no significant differences between the groups for each measurement (Fig. 3).

PONV was the most common analgesic-related side effect in both groups. Overall, PONV incidence was higher in Group N compared with Group K (59\% vs. 34\%, P = 0.015) (Table 3). The PONV incidences were significantly higher in Group $\mathrm{N}$ than Group K in female (Group K: 20/35 patients [63\%] vs. Group N: $29 / 33$ patients [88\%], $\mathrm{P}=0.011$ ) but, not in non-smoker patients (Group K: 16/34 patients [47\%] vs. Group N: 16/26 patients [62\%], $\mathrm{P}=0.394)$. In groups $\mathrm{K}$ and $\mathrm{N}$, the number of patients who experienced dizziness ( 1 vs. 3 ), tachycardia (1 vs. 2 ), hypotension ( 3 vs. 2 ), and bradycardia ( 1 vs. 1 ) were similar, and no patients experienced sweating, urinary retention, pruritus, somnolence, and respiratory depression.

\section{Discussion}

This study examined the analgesic efficacy and side effects of ketorolac and nefopam that were co-administered with fentanyl via IV-PCA for postoperative analgesia. In the current study, 
there were no significant differences in postoperative analgesics consumption and pain intensity between the ketorolac-fentanyl and nefopam-fentanyl combinations. However, overall incidences of PONV for postoperative $48 \mathrm{~h}$ were significantly higher in Group N than in Group K (59\% vs. 34\%).

The use of nefopam or NSAIDs such as ketorolac for the treatment of postoperative pain is a common practice. However, NSAIDs and nefopam have been used as sole analgesics only for mild to moderate postoperative pain because they have an analgesic ceiling effect. Opioids are more effective than NSAIDs

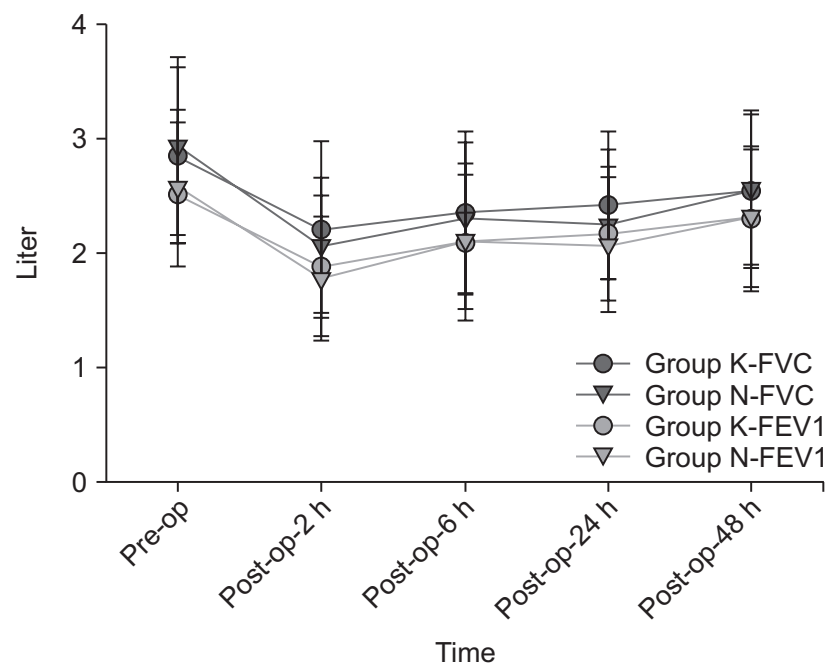

Fig. 3. The recovery of forced vital capacity (FVC) and forced expiration volume in $1 \mathrm{sec}$ (FEV1) showed no significant differences between the groups at each measurement time point. Group $\mathrm{K}$ and $\mathrm{N}$ are the ketorolac-fentanyl and nefopam-fentanyl combinations, respectively. for moderate-to-severe acute pain [20,21]. Opioids are the cornerstone of postoperative pain management for severe pain, but they can cause PONV, pruritus, somnolence, and respiratory depression. Co-administration of adjuvant analgesics to an opioid regimen reduced opioid consumption, which could lead to a decrease in opioid-related side effects in the postoperative period. Cepeda et al. [21] demonstrated that the risk of side effects was increased by $1.3 \%$ for every 1-mg increase in morphine consumption. Also, they found that the addition of ketorolac to opioids decreased the risk of opioid-related side effects in the early postoperative period because of a considerable reduction in opioid requirements. Although the opioid-sparing effect of analgesics varied by surgery types and study design, the effects of nefopam and ketorolac seem to be similar and ranged from $20 \%$ to $50 \%[21,22]$.

Nefopam is a non-opioid, non-steroidal, centrally acting analgesic. Although the pharmacological mechanism of nefopam is unclear, its analgesic mechanisms involve the inhibition of reuptake of monoamine and action on $\alpha_{2}$-adrenergic and $\mathrm{N}$ methyl-D-aspartate receptors [23,24]. Nefopam does not bind to opioid receptors and does not induce an anti-inflammatory effect such as NSAIDs [25]. Ketorolac is an IV injectable NSAID that has antipyretic, analgesic, and anti-inflammatory properties. It inhibits COX and hinders the activation of peripheral nociceptor system. Nefopam, ketorolac, and fentanyl have different inherent analgesic mechanisms. Multi-pharmacologic PCA regimens have the definite advantages in minimizing the risks of analgesic-related side effects and achieving more effective pain control. Therefore, nefopam and ketorolac could be good options for such purposes.

Table 3. Incidences of Postoperative Nausea and Vomiting and Use of Rescue Antiemetics

\begin{tabular}{|c|c|c|c|c|}
\hline & & $\begin{array}{c}\text { Group K } \\
(\mathrm{n}=76)\end{array}$ & $\begin{array}{r}\text { Group N } \\
(\mathrm{n}=66)\end{array}$ & $P$ value \\
\hline \multirow[t]{3}{*}{$0-2 \mathrm{~h}$} & Nausea & $21(28 \%)$ & $26(39 \%)$ & 0.191 \\
\hline & Vomiting & $4(5 \%)$ & $4(6 \%)$ & 0.873 \\
\hline & Rescue medications & $12(16 \%)$ & $10(15 \%)$ & 0.898 \\
\hline \multirow[t]{3}{*}{$2-6 \mathrm{~h}$} & Nausea & $16(21 \%)$ & $27(41 \%)^{*}$ & 0.017 \\
\hline & Vomiting & $3(4 \%)$ & $2(3 \%)$ & 0.921 \\
\hline & Rescue medications & $7(9 \%)$ & $10(15 \%)$ & 0.407 \\
\hline \multirow[t]{3}{*}{$6-24 \mathrm{~h}$} & Nausea & $7(9 \%)$ & $13(20 \%)$ & 0.121 \\
\hline & Vomiting & $1(1 \%)$ & $1(2 \%)$ & 0.540 \\
\hline & Rescue medications & $0(0 \%)$ & $5(8 \%)^{*}$ & 0.047 \\
\hline \multirow[t]{3}{*}{$24-48 \mathrm{~h}$} & Nausea & $4(5 \%)$ & $7(11 \%)$ & 0.383 \\
\hline & Vomiting & $0(0 \%)$ & $1(2 \%)$ & 0.944 \\
\hline & Rescue medications & $0(0 \%)$ & $0(0 \%)$ & NA \\
\hline \multirow[t]{3}{*}{$0-48 \mathrm{~h}$} & Nausea & $26(34 \%)$ & $39(59 \%)^{*}$ & 0.015 \\
\hline & Vomiting & $5(7 \%)$ & $7(11 \%)$ & 0.577 \\
\hline & Rescue medications & $14(18 \%)$ & $20(30 \%)$ & 0.145 \\
\hline
\end{tabular}

Data are presented as number of patients along with their percentage. Group $\mathrm{K}$ and $\mathrm{N}$ are the ketorolac-fentanyl and nefopam-fentanyl combinations, respectively. ${ }^{*} \mathrm{P}<0.05$ compared with Group K. 
For the comparison of analgesic efficacy between nefopamfentanyl and ketorolac-fentanyl combinations, an equianalgesic dose was applied for both groups. Although no reports directly compared the analgesic potency between ketorolac and nefopam, the potency of nefopam $20 \mathrm{mg}$ and ketorolac $30 \mathrm{mg}$ were comparable with the potency of $12 \mathrm{mg}$ morphine $[18,19]$. Therefore, the authors hypothesized that $20 \mathrm{mg}$ of nefopam and $30 \mathrm{mg}$ of ketorolac may have similar analgesic potency even though the relative analgesic potency could be different from pain intensity when compared with morphine. In the current study, the results showed almost similar cumulative postoperative analgesic consumptions at postoperative $48 \mathrm{~h}(93.4 \pm 24.0 \mathrm{ml}$ vs. $92.9 \pm 26.1$ $\mathrm{ml}$ ) with similar pain intensities between the groups. It seems that nefopam $20 \mathrm{mg}$ and ketorolac $30 \mathrm{mg}$ are equianalgesic.

The mu opioid agonists, such as fentanyl and morphine, have similar side effects including nausea, dry mouth, constipation, vomiting, pruritus, sedation, and respiratory depression regardless. The most common postoperative side effects of opioid use are PONV. Ketorolac is known to be associated with several side effects related to the inhibition of COX, including gastrointestinal mucosal damage, platelet dysfunction, and renal toxicity. In comparison with fentanyl and ketorolac, nefopam does not cause sedation, respiratory depression, platelet dysfunction, or renal impairment, but it increases the incidence of sweating and tachycardia. In the current study, PONV incidences were 59\% and 34\% in Group N and K, respectively. The incidence of PONV in patients who underwent laparoscopic cholecystectomy with fentanyl-based postoperative pain control was $60-65 \%$ $[26,27]$. Although co-administration of nefopam could decrease fentanyl consumption, the nefopam-fentanyl combination did not reduce the incidence of PONV. Because the current study did not directly compare the nefopam-fentanyl combination versus fentanyl alone, caution is advised on the interpretation of our results. Yoon et al. [28] demonstrated that nefopam reduces the incidence of PONV compared with a combination of morphine and ketorolac in IV-PCA. Our study compared nefopamfentanyl with ketorolac-fentanyl combinations but, the study compared nefopam alone and morphine-ketorolac combination. Therefore, the discrepancy in the results could be due to the addition of an opioid. None of the patients showed a postoperative bleeding tendency in Groups $\mathrm{K}$ although physicians may be apprehensive about coagulopathy. Although previous studies have reported sweating (9-24\%), tachycardia (12-21\%), and hypertension (10-22\%) as common side effects of nefopam, only two patients experienced tachycardia (3\%), and none of them experienced sweating [29]. These low incidences may be due to the dilution and slow infusion of nefopam.

There are two limitations in the current study. First, incidences of analgesic-related side effects may have been underestimated. Although patients were observed continuously for the development of side effects in the PACU for the first $2 \mathrm{~h}$, further evaluations were done at the surgical ward through medical records and questions to the patient at each measurement time point. Therefore, incidences of temporarily developed side effects, such as dizziness, sweating, hypotension, bradycardia, tachycardia, and somnolence may have been omitted. Second, although $73 \%$ of the subjects had two or three major PONV risk factors, they did not receive prophylactic antiemetics, which did not conform to PONV guidelines. However, patients were under close observation and received rescue antiemetic medications immediately when they showed vomiting or required rescue medications.

In conclusion, the current study demonstrated that the analgesic efficacies of ketorolac and nefopam, which were coadministered with fentanyl for postoperative pain management as adjuvant analgesics, were similar. However, PONV incidence was higher in the nefopam-fentanyl combination compared with that in the ketorolac-fentanyl combination. The incidences of other side effects were comparable between both combinations.

\section{ORCID}

Ji-Seon Son, https://orcid.org/0000-0002-6672-4576

Seonghoon Ko, https://orcid.org/0000-0003-2742-9985

\section{References}

1. Khan MI, Walsh D, Brito-Dellan N. Opioid and adjuvant analgesics: compared and contrasted. Am J Hosp Palliat Care 2011; $28: 378-83$.

2. Friedman Z, Katznelson R, Phillips SR, Zanchetta C, Nistor OI, Eisen LB, et al. A randomized double-blind comparison of a morphinefentanyl combination vs. morphine alone for patient-controlled analgesia following bowel surgery. Pain Pract 2008; 8: 248-52.

3. Woodhouse A, Ward ME, Mather LE. Intra-subject variability in post-operative patient-controlled analgesia (PCA): is the patient equally satisfied with morphine, pethidine and fentanyl? Pain 1999; 80: 545-53.

4. Shapiro A, Zohar E, Zaslansky R, Hoppenstein D, Shabat S, Fredman B. The frequency and timing of respiratory depression in 1524 postoperative patients treated with systemic or neuraxial morphine. J Clin Anesth 2005; 17: 537-42.

5. Curry TJ, Jarosch J, Pacholok S. Are direct to consumer advertisements of prescription drugs educational?: comparing 1992 to 2002 . J Drug Educ 2005; 35: 217-32.

6. White PF. Multimodal analgesia: its role in preventing postoperative pain. Curr Opin Investig Drugs 2008; 9: 76-82. 
7. Maund E, McDaid C, Rice S, Wright K, Jenkins B, Woolacott N. Paracetamol and selective and non-selective non-steroidal antiinflammatory drugs for the reduction in morphine-related side-effects after major surgery: a systematic review. Br J Anaesth 2011; 106: $292-7$.

8. Kim JA, Kim TH, Yang M, Gwak MS, Kim GS, Kim MJ, et al. Is intravenous patient controlled analgesia enough for pain control in patients who underwent thoracoscopy? J Korean Med Sci 2009; 24: 930-5.

9. Piercey MF, Schroeder LA. Spinal and Supraspinal sites for morphine and nefopam analgesia in the mouse. Eur J Pharmacol 1981; 74: 135-40.

10. Aveline C, Gautier JF, Vautier P, Cognet F, Hetet HL, Attali JY, et al. Postoperative analgesia and early rehabilitation after total knee replacement: a comparison of continuous low-dose intravenous ketamine versus nefopam. Eur J Pain 2009; 13: 613-9.

11. Richebé P, Picard W, Rivat C, Jelacic S, Branchard O, Leproust S, et al. Effects of nefopam on early postoperative hyperalgesia after cardiac surgery. J Cardiothorac Vasc Anesth 2013; 27: 427-35.

12. Yoo JY, Lim BG, Kim H, Kong MH, Lee IO, Kim NS. The analgesic effect of nefopam combined with low dose remifentanil in patients undergoing middle ear surgery under desflurane anesthesia: a randomized controlled trial. Korean J Anesthesiol 2015; 68: 43-9.

13. Ready LB, Brown CR, Stahlgren LH, Egan KJ, Ross B, Wild L, et al. Evaluation of intravenous ketorolac administered by bolus or infusion for treatment of postoperative pain. A double-blind, placebo-controlled, multicenter study. Anesthesiology 1994; 80: 1277-86.

14. Leykin Y, Casati A, Rapotec A, Dal Sasso M, Barzan L, Fanelli G, et al. A prospective, randomized, double-blind comparison between parecoxib and ketorolac for early postoperative analgesia following nasal surgery. Minerva Anestesiol 2008; 74: 475-9.

15. Moffat AC, Kenny GN, Prentice JW. Postoperative nefopam and diclofenac. Evaluation of their morphine-sparing effect after upper abdominal surgery. Anaesthesia 1990; 45: 302-5.

16. Remérand F, Le Tendre C, Rosset P, Peru R, Favard L, Pourrat X, et al. Nefopam after total hip arthroplasty: role in multimodal analgesia. Orthop Traumatol Surg Res 2013; 99: 169-74.

17. Apfel CC, Läärä E, Koivuranta M, Greim CA, Roewer N. A simplified risk score for predicting postoperative nausea and vomiting: conclusions from cross-validations between two centers. Anesthesiology 1999; 91: 693-700.

18. Sunshine A, Laska E. Nefopam and morphine in man. Clin Pharmacol Ther 1975; 18: 530-4.

19. O'Hara DA, Fragen RJ, Kinzer M, Pemberton D. Ketorolac tromethamine as compared with morphine sulfate for treatment of postoperative pain. Clin Pharmacol Ther 1987; 41: 556-61.

20. Cepeda MS, Vargas L, Ortegon G, Sanchez MA, Carr DB. Comparative analgesic efficacy of patient-controlled analgesia with ketorolac versus morphine after elective intraabdominal operations. Anesth Analg 1995; 80: 1150-3.

21. Cepeda MS, Carr DB, Miranda N, Diaz A, Silva C, Morales O. Comparison of morphine, ketorolac, and their combination for postoperative pain: results from a large, randomized, double-blind trial. Anesthesiology 2005; 103: 1225-32.

22. Du Manoir B, Aubrun F, Langlois M, Le Guern ME, Alquier C, Chauvin M, et al. Randomized prospective study of the analgesic effect of nefopam after orthopaedic surgery. Br J Anaesth 2003; 91: 836-41.

23. Rosland $\mathrm{JH}$, Hole $\mathrm{K}$. The effect of nefopam and its enantiomers on the uptake of 5-hydroxytryptamine, noradrenaline and dopamine in crude rat brain synaptosomal preparations. J Pharm Pharmacol 1990; 42: 437-8.

24. Fernández-Sánchez MT, Díaz-Trelles R, Groppetti A, Manfredi B, Brini AT, Biella G, et al. Nefopam, an analogue of orphenadrine, protects against both NMDA receptor-dependent and independent veratridine-induced neurotoxicity. Amino Acids 2002; 23: 31-6.

25. Conway AC, Mitchell CL. Analgesic studies with nefopam hydrochloride. Arch Int Pharmacodyn Ther 1977; 226: 156-71.

26. Wang J, Ho ST, Liu YH, Lee SC, Liu YC, Liao YC, et al. Dexamethasone reduces nausea and vomiting after laparoscopic cholecystectomy. Br J Anaesth 1999; 83: 772-5.

27. Pandey CK, Priye S, Ambesh SP, Singh S, Singh U, Singh PK. Prophylactic gabapentin for prevention of postoperative nausea and vomiting in patients undergoing laparoscopic cholecystectomy: a randomized, double-blind, placebo-controlled study. J Postgrad Med 2006; 52: 97 100.

28. Yoon JU, Byeon GJ, Cheon JH, Choi YM, Ri HS, Baik SW. Post-operative intravenous patient-controlled analgesic efficacy of morphine with ketorolac versus nefopam after laparoscopic gynecologic surgery: a randomized non-inferiority trial. Korean J Anesthesiol 2016; 69: 161-6.

29. Evans MS, Lysakowski C, Tramèr MR. Nefopam for the prevention of postoperative pain: quantitative systematic review. Br J Anaesth 2008; 101: 610-7. 